\title{
Introduction
}

In the mid-1980s, non-governmental organisations (NGOs) began to flow into poor countries to help them improve their lives and livelihoods. Malawi, a small country in south-central Africa, was an attractive location: it is one of the poorest countries in the world, it is peaceful and has little crime, English is the official language, it has reasonable roads such that NGO staff can move around relatively easily. In the period 19851989 there were 16 registered NGOs; in 2001-2005 there were 196 NGOs, half of them focused on HIV prevention (Morfit 2011). In the first phase, NGOs typically focused on implementing programmes that would improve health (e.g. clean water) and agriculture. Increasingly, however, they were concerned with improving the situation of women and girls, who were considered to be particularly vulnerable to harms. A hierarchy of NGOs was established. At the top were international NGOs such as Save the Children, Catholic Relief Services and CARE, at the bottom were small organisations based in district capitals.

A major consequence of the establishment of NGOs was that it provided jobs in the formal economy for educated Malawians. Those with a PhD or an MA worked in offices in the Capital, Lilongwe, those with only a BA were stationed in district capitals, and those who had only a secondary education picked up jobs whenever they could, such as working on a short-term survey. The level of education determined not only one's income but also their social status and whether they lived in one of the two large cities or in a district capital. Not surprisingly, those at the 
top of the income and social status ladder looked down on those who had little or no education.

In 2008, I was working as a Programme Manager for a sexual and reproductive health $\mathrm{NGO}$ based in London. As part of my job, I went to Malawi to monitor a HIV prevention programme, funded by the Department for International Development (DfID). I was speaking to a Malawian woman in Blantyre (Malawi's second largest city, located in the South of the country) who set up a Women and AIDS Community Based Organisation (CBO), which was indirectly funded by DfID. She was HIV positive. She spoke English and raised the topic about certain sexual practices said to be risky for the spread of HIV, often referred to in the literature, and by people in Malawi, as 'harmful cultural practices'. One particular practice grabbed my attention. It is called fisi), which means 'hyena' in English. The story recounted to me was about a hyena. In this case the hyena is a man, who is hired to have sex with young women who participate in initiation ceremonies when they start menstruating. But the hyena practice has several other meanings, which I will come to later. A few years later, an NGO ran a banner in the daily newspapers - see Fig. 1.1: it was at the bottom of the first page, with a background of red and black, and said 'STOP Harmful cultural practices'. The banner was produced by UNICEF.

I arrived in Lilongwe in 2008 to begin my research and was picked up by my friend who worked for an AIDS NGO. We travelled to Blantyre and she invited me to stay at her house with her family. I asked her if I could work from her office and was fortunate enough to be given desk space.

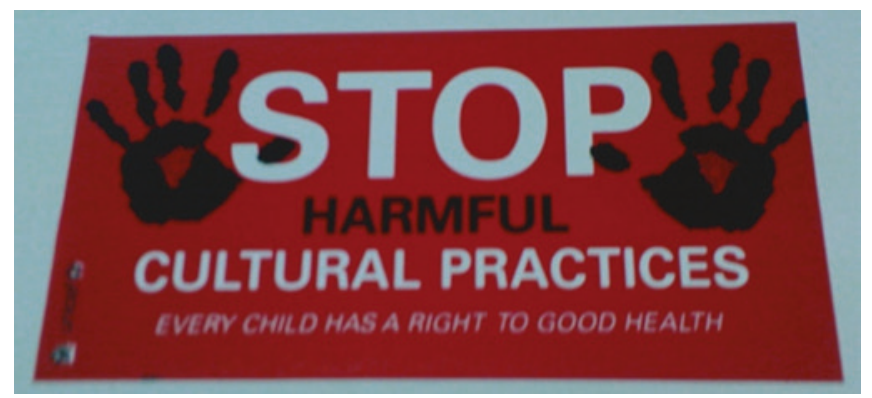

Fig. 1.1 Stop harmful cultural practices banner (Photo taken on 10 July 2009. Malawi: Author) 
This was an invaluable opportunity as I shared an office with a policy officer and this enabled me to meet people passing by my desk. I was hoping that I would identify an organisation with which to carry out my research. It was not long after I was in my new surroundings that the Executive Director of a small CBO, based in the district of Mulanje, asked me what I was doing there. He then excitedly told me about the fisi practice. He said for him, fisi meant three things:

1. Surrogacy - if you see a stick on the door you should not go in as you know something is going on. 2. Kuchotsa/kutsatsa fumbi - sexual cleansing. During initiation ceremonies when a girl has reached puberty and is menstruating she is taught how to entertain her husband. The girl could be from 7,8 or 9-12 years old. She is told she must sleep with someone otherwise she will have problems. The person she will sleep with may be big or young. The impact of this a) early/unwanted pregnancy b) drop out at school c) early marriage d) contract HIV. 3. Kuchotsa milaza - concept whereby in Mulanje you may go out and you have left your husband and you sleep with other men. So you are forced to sleep with someone else who is the relative of the husband to be forgiven for sleeping with someone else. (Journal entry 26 August 2008)

He invited me to visit his village where he ran the $\mathrm{CBO}$ to find out more about the fisi. However after I visited his village, my friend, the Director of the AIDS NGO, told me that the practice was not particularly prevalent in that part of Malawi, and that he had exaggerated the story so that I would visit and perhaps help him access funding.

So I returned to my desk in Blantyre. Along came the Executive Director of a youth CBO. He told me 'there are lots of cultural practices that go on in my village' and therefore it would be a perfect site to conduct my research. He then described at length the practice of kusasa fumbi and then told me:

When initiation ceremony comes to an end, the village leaders or opinion leaders in the village, they plan for the men to have sex with girls. The men are from a different community. Also women are chosen to have sex with boys. They are also from a different village. Women get women and men get men. They are paid in food. No money. Condoms are not used. There is a need to exchange fluids so cannot use condoms. (Journal entry, 26 August 2008) 
I was amazed that they volunteered to tell me about the fisi practice without having interviewed them. I then became aware of a widespread misconception in the NGO sector and beyond into the world of international donors that so-called 'harmful cultural practices' were the main driver of the AIDS epidemic in Malawi. It was the educated Malawian elites who described these practices at length, expounding on the risks they presented and efforts to stamp them out, while at the same time weaving into the discourse other fashionable interests of international agencies, such as the particular vulnerability of women, especially young women, to contracting HIV. It is important to highlight here that these stories about harmful cultural practices came from educated Malawians who speak English, not the villagers. But the link between these 'harmful cultural practices' and the epidemic was never supported by evidence. For example, while it is known that the prevalence of AIDS among widows is higher than among married women, there had been-and continues to be-no evidence that this was due to widow inheritance (when a woman's husband dies, she lives with her husband's brother) rather than to years of marriage to a man who had died of AIDS. From a biomedical perspective the latter is more likely.

Biomedical evidence shows that 'harmful cultural practices' are not the main contributors to the AIDS epidemic. So what is interesting is why so many educated Malawians working in the AIDS sector told me about the practices, not the villagers, and blamed them for the spread of AIDS.

In this book I analyse the responses these practices evoke: these include lawyers, researchers, policymakers, government ministers, NGO and INGO staff, staff working for bilateral and multilateral agencies, national and district officials and health workers.

This book explores policy surrounding HIV prevention. It draws attention to the ways that the elites in Malawi-people who stand out because they are educated and thus speak and read English, the official language, in contrast to the majority of Malawians who live in villages and have, at best, completed primary school. Those who have a university degree dominate the policy arena: they are staff in the civil service and they implement the programmes of NGOs and bilateral or multilateral agencies programmes (Watkins and Swidler 2009; Myroniuk 2011). They are middle-class people in government positions or working in International NGOs. 
The educated elites I met almost invariably disparage those who have less education. I found that upon meeting an educated Malawian, they often began the conversation by telling me about what came to be called the 'harmful cultural practices' of the uneducated villagers. They thus make it clear to expatriates who buy into the distorted accounts of the elites.

I show that the epistemic community in Malawi (epistemic community includes international donors working on HIV and AIDS as well as the Malawian elite) are reframing both sexual cultural practices and women's rights concepts in the context of what is widely considered an emergency, the AIDS epidemic. This epistemic community comprises those working in the field of AIDS, who frame narratives about AIDS to achieve other goals, both ideal and pragmatic, for example for the purposes of self-preservation and self-interest. Haas' (1992) notion of the 'epistemic community' is particularly useful for conceptualising the HIV prevention community in Malawi. Haas describes an epistemic community as 'a network of professionals with recognised expertise and competence in a particular domain or issue-area' (Haas 1992, p. 3). He says that epistemic communities are groups of professionals, from a variety of different disciplines, which produce policy-relevant knowledge about complex technical issues (Haas 1992, p. 16). This book makes the case that the Malawian elite is influencing the policy agenda on AIDS and harmful cultural practices. This book also examines how others-e.g. international staff working for International NGOs, bi- and multilateral donors - adopted the views provided by the Malawian elite without questioning the evidence. But why would they? First, donors and NGOs have little interest in establishing an evidentiary base for any of their programmes $^{1}$ and second, UNAIDS did not want to disseminate the evidence about low probabilities.

I also explore how evidence is produced in the context of AIDS and how certain sexual cultural practices have been co-opted by the NGO discourse in order to explain why HIV prevalence is so high in Malawi as well as other African countries. ${ }^{2}$ My analysis is oriented around how different narratives on AIDS are framed, and what and how evidence is used to support them. As I show, these narratives are not based on face-to-face encounters with women involved in these practices. What is under consideration is the way the Malawian elites present rural people as backward by deploying the phrase 'harmful cultural practices': the 
elites then blame the AIDS epidemic on these practices. What my theoretical framework shows is how this constructed and epidemiologically inaccurate narrative has been taken up and endorsed by international donors.

Initially, this research intended to examine the contribution of sexual cultural practices such as widow inheritance and initiation rites (Munthali and Zulu 2007) to the transmission of HIV (Coombes 2001; Chizimba et al. 2004). However, after I read about the exotic cultural practices that are considered harmful (Malawi Human Rights Commission 2006), and the research of epidemiologists (e.g., Gray et al. 2001; Boily et al. 2009 ) it was apparent that many, perhaps most, of the cultural practices are unlikely to contribute significantly to the epidemic. Far more important are everyday practices, such as unprotected sex with multiple sexual partners both before and after marriage (Smith and Watkins 2005; Chimbiri 2007; Dimbuene et al. 2014).

These everyday practices are also part of the traditional culture: in particular, when a man asks a woman or girl to have sex, the man must offer her resources in exchange. Wealthy men drive the sexual exchange, and have significantly higher levels of HIV, yet there are few, if any, NGO programmes that target men for behaviour change.

In my conversations with Malawians, the practice of fisi is invariably introduced. Yet as well as the absence of the epidemiological evidence to show that the fisi practice is of low risk, there is also a lack of evidence to suggest the fisi practice is widespread to the extent that it would significantly increase HIV prevalence rates in Malawi. When those in the NGO community who are concerned with fisi talk about it, they invariably refer to two of the 28 districts, Nsanje and Mangochi as examples. For example, a fisi (a male adult who has sexual intercourse with newly initiated girls) is uniquely practiced in societies such as among the Chewa and among the Yao in which their form of initiation for girls (called chinamwali and chindakula respectively) encourages sexual intercourse for initiates (Malawi Human Rights Commission 2006, p. 8). But we see also the role of fisi in widow cleansing, fisi for Procreation, Birth Cleansing (kulimbitsa mwana), Death Cleansing and for Cleansing Infidelity (Malawi Human Rights Commission 2006, p. 8). In my conversations with Malawians it was also assumed by them that the fisi was infected.

Although the fisii are involved in a variety of rituals, the NGOs focus on young girls, probably because so many of them are engaged in 
helping women and girls. I did not hear much about fisi and sexual cleansing for someone who died. It is also important to mention that the fisii are paid.

Further, there is a lack of anthropological evidence to argue that this practice contributes significantly to high HIV rates. Studies in Malawi (see, e.g., Skinner et al. 2013; Munthali et al. 2006; Munthali and Zulu 2007; Kamlongera 2007; Banda and Kunkeyani 2015) and several donor and government-funded studies on sexual cultural practices and AIDS in Malawi (Kornfield and Namate 1997; Matinga and McConville 2003; Malawi Human Rights Commission 2006; Kalipeni and Garrard 2004; College of Medicine 2005; Kadzandira and Zisiyana 2006; Chimombo 2006; Conroy et al. 2006) have been used to explain how sexual cultural practices are spreading HIV in Malawi, yet these results have been amplified outside these studies' findings.

Why is there then so much focus on something that in numerical terms at best has a minor effect on the increase of AIDS at a national level? The fisi practice does not contribute significantly to the spread of HIV for four reasons. First, epidemiological evidence reveals that the probability of infection during one heterosexual act is startlingly low. ${ }^{3}$ Second, there is a lack of evidence to demonstrate how prevalent the practice is in Malawi. Third, although studies have been carried out on sexual cultural practices in Malawi, there is little empirical evidence to demonstrate that the fisi practice is contributing to the spread of HIV at a national scale. Fourth, although the emphasis on fisi in HIV discourse has been on poor young women (15-24) as drivers of the epidemic, HIV prevalence rates are higher in urban areas among women aged 30-34 who are in the highest wealth quintile in Malawi (Mishra et al. 2007). This category of women is significantly different from girls and young women living in rural areas aged 15 and below who may be participating in the fisi practice. This category of women is also different from widows where the term fisi is used for widow cleansing rites.

Narratives linking sexual cultural practices and HIV have been constructed which blame the fisi practice for the spread of AIDS. The fisi practice is being used as a scapegoat for three main reasons. First, the elites working in NGOs need constant donor funding. Thus, maintaining the fisi narrative to attract donor funding contributes to the stability of the policies and programmes directed to reduce transmission and thereby ensuring their jobs remain intact. Second, to project the issue of AIDS as 
a disease being spread by rural people, which detracts attention from the educated elite's sexual behaviour. Third, it supports a Christian narrative that sees those practising African Traditional Religion as backwards. This narrative has been amplified because it reflects the modernising agenda of key elites in Malawi, as opposed to reflecting a proportionate threat to the spread of AIDS. This deflects attention from high-risk sexual practices such as multiple sexual partners particularly among urban and affluent Malawians. AIDS policies should be designed to address contemporary patriarchal constructions of gender and power than a one-off highly un-evidenced traditional sexual practice. What I argue is there is evidence of a lack of evidence to support the policy to eradicate the practice of fisi because of the link with HIV.

\section{The Argument}

In this book, I argue that a complex interplay of interests has led to the construction of the narrative that the sexual cultural practice of fisi contributes significantly to the spread of AIDS. I argue this complexity can be best understood through three sets of arguments.

The first and main argument is that a narrative of blame is maintained by national elites in Malawi, to ensure that HIV is kept on the development policy agenda within the institutions in which they work, thus attracting donor funding and retaining the elites' professional status and salaries. Although the elites are concerned about getting the virus, this blame narrative ensures that the target group for intervention is rural communities rather than the elites themselves. This argument complements the theoretical work of Mosse (2011) who has pioneered the use of what he terms the ethnography of aid, using this methodology to unravel the complex layers and actors that combine in the production of development policy and practice. Mosse (2011) highlights the importance of actor relationships in constructing policy, as well as emphasising the importance of policy in mediating social and professional relationships (2011, p. 10). Mosse builds on the work of Harper (1998) and Wood (1998) and describes actor relationships as 'complex relationships including negotiations over status, access, disciplinary points of view, team leadership struggles, conflict management or compliance with client frameworks defining what counts as knowledge' (2011, p. 10). In terms of policy, Mosse argues that 'policy ideas gain currency because they are socially appropriate....they can submerge ideological differences, 
allowing compromise, room for manoeuvre or multiple criteria of success, thus winning supporters by mediating different understandings of development' (2011, p. 11). Like Mosse, my study emphasises policy construction as a process mediated by those involved in the policy process as well as highlighting the importance of the policy itself. In my research, those mediating the process were the people I interviewed working on HIV prevention. The policy that these actors are mediating is that traditional sexual cultural practices should be eradicated because they argue these practices are the main driver of the HIV pandemic in Malawi. Additionally, Mosse asserts that:

The interests of national elites and the electoral concerns of those in power affect the state's policy choices, sector priorities, and programs, with important consequences for the poor. Equally, well-intentioned sector reform programs can run aground where they challenge vested interests, and democratic reforms often have limited or unpredictable effect on power relations. (Mosse 2004, p. 51)

This is relevant as I argue that one reason national elites are able to influence the HIV policy agenda is related to the desire of donorsand the NGOs that they support-to be given a simple and rational explanation for high transmission that they can easily focus implementation around. Mosse (2011) also makes reference to international professionals who have to secure their positions within institutional and social contexts, which he says are hugely complex. Although Mosse in this context mainly refers to international professionals, I show that the same is true for national professionals working in development in Malawi, which means that groups of specialists and professionals need to sustain certain agendas to maintain their own status and positions. This argument is also linked to the work of Gibson et al. (2005) who argue that the structure of foreign aid can produce perverse outcomes that impede effectiveness and that the aid system is based on a set of power relations between actors ultimately driven by money.

These points are relevant to my argument: as I show in chapter four that organisations and agencies working on AIDS are major employers in Malawi. Although these development organisations are unlikely to disappear, they are also unstable as they rely on external funding. Successive themes come and go (e.g. HIV/AIDS, governance, gender, climate change) and with them jobs appear and disappear. Maintaining 
the narrative that the sexual cultural practice of fisi is spreading HIV can ensure policy and programmes directed to reduce HIV transmission continue. Today we see that interest in AIDS is declining so those working in NGOs are anxious: what would be the next 'big issue' that would support them? ${ }^{4}$ This would most certainly be the case in many countries in sub-Saharan Africa that heavily depend on donors.

My second argument is that AIDS is presented by national, educated elites as a disease being spread by those living in rural areas, most of whom have little education beyond the first years of primary school and are often referred to by the elites as 'ignorant'. The narrative of sexual cultural practices thus absolves the educated elite from contributing to the epidemic as well as detracting attention from higher HIV prevalence rates in urban areas. This argument is situated within and supported by the literature on what is called 'the underdeveloped other' (Gramsci and Hoare 1971; Escobar 1988; Hobart 1993; Quarles van Ufford and Saleminck 2006). As I highlight in this book, this 'othering' is a result of those elites working in HIV prevention providing explanations to 'problems' that satisfy donors and therefore ensure continued funding. As a result, the educated elites who are perceived as civilised, distance themselves from rural people who they perceive as uncivilised. As Escobar (1995) asserts "rather than being eliminated by development, many "traditional cultures" survive through their transformative engagement with modernity' (1995, p. 219). Elites in Malawi maintain their positions through their engagement with western discourses on modernity and distance themselves from Malawians living in rural areas who they perceive as backwards. The Malawian elites are making themselves look like the modern, unproblematic group that donors should work with.

The third argument is that the Malawian elites see those practising African Traditional Religion as backwards. Those who have converted to Christianity perceive themselves as modern and progressive. This argument has been guided by postcolonial theorists including Bassey (1999), Kitching (1982), Ngũgi wa Thiong'o (1986), and Lloyd (1967). They describe the elite in sub-Saharan Africa as the postcolonial elite as they have converted to Christianity. Postcolonial theory is thus relevant to my study as it follows on from the imperialist idea of westernising the backward. What it demonstrates is that the elites in Malawi are perpetuating an imperialist narrative by blaming people who practise African Traditional Religion as backwards, thereby establishing their modernity. Further, 
Christianity allows them to be seen as consistent with western discourses on modernity.

I have presented three sets of arguments to explain why this narrative of blame is prevalent in Malawi, and these are interlocking. Several theories have influenced my argument: anthropology of development theory, postcolonial theory, theories on the policy process, elite theory and epidemiology. I will explore these theories in Chapter 2.

Malawi has suffered from one of the highest HIV prevalence rates in sub-Saharan Africa, with HIV prevalence among sexually active adults 15-49 years of age estimated at 10\% (Joint United Nations Programme on HIV/AIDS [UNAIDS] 2013). It is also one of the poorest countries: its ranking on the UN's Human Development Index is 0.385 , below the mean for sub-Saharan Africa of 0.389; and its per capita GNI is estimated at \$911, below the mean for sub-Saharan Africa of \$2050 (UN 2010). The population is predominantly rural (about $85 \%$ ), and contains many ethnic groups with varying traditional cultural practices (Kornfield and Namate 1997; Matinga and McConville 2003; Malawi Human Rights Commission 2006). Particularly relevant for this research is the role of donors (Crewe and Harrison 1998; Mosse 2005). International donors (i.e. bi- and multilateral agencies) have been quite generous to Malawi (OECD-DAC 2007; UN 2006), perhaps in part due to its extreme poverty and the severity of its AIDS epidemic, as well as other health issues. Given its political stability, and the widespread use of English in government and the NGOs, Malawi is a relatively pleasant place for international aid workers to work which in part accounts for the large expatriate aid community.

At the time of my research, HIV prevalence rates in Malawi were higher in the south $(20-22 \%)$ than the north $(8 \%)$ and centre $(7 \%)$; and higher in urban than rural areas (MDHS 2004). For example, while $18 \%$ of urban women are HIV positive, the corresponding proportion for rural women is $13 \%$. For men, the urban-rural difference in HIV prevalence is even greater; men living in urban areas are nearly twice as likely to be infected than those living in rural areas (16 and $9 \%$, respectively) (MDHS 2004, p. 231). As noted previously, this is very significant since sexual cultural practices are reported to be largely rural practices, yet HIV prevalence is lower in rural areas.

Further, although donors and NGOs have featured young women and girls between age 15 and 24 as particularly vulnerable to HIV in 
sub-Saharan Africa (UNAIDS 2004, p. 2), at the time of this study HIV prevalence in Malawi was higher among women aged 30-34 (18\%) compared to $3.7 \%$ of women aged 15-19 (MDHS 2010). In addition, no data existed for HIV prevalence rates among girls under the age of 15 . Women are tested at antenatal clinics, to which few girls under 15 would attend. And yet this is the demographic partaking in initiation ceremonies, which supports my argument that those blaming sexual cultural practices for the spread of HIV cannot support their case. In terms of education and wealth, HIV prevalence rates are highest among women with a secondary education and above (15.1\%) compared to those women with no education (13.6\%). In terms of income, those women with the highest rates of HIV were in the top wealth quintile.

Since the mid-1980s and the movement towards the privatisation of foreign aid, donor funding has been channeled to support NGOs. A study showed that the number of registered NGOs increased from a handful in 1964, at the time of Independence, to approximately 120 in 2003 (Morfit 2008). With the vast number of NGOs and development agencies operating in the country aid becomes tightly clustered resulting in and reinforcing the 'donor-darling'/'donor orphan' divide (Koch 2007). Registration of NGOs is incomplete, but a proxy measure-the sheer number of advertisements for NGO positions in the newspapersshows a dramatic increase, as I anecdotally noted during my fieldwork in Malawi.

The NGO positions are filled by the Malawian elites. The international elites (with PhDs from abroad) and national elites (with university degrees) did not grow up in the rural areas and almost invariably did their schooling in Lilongwe or Blantyre (Watkins and Swidler 2013). The disparagement by the elites of harmful cultural practices is a way of establishing their modernity, ensuring distance from what they call the 'backward' rural areas. The NGO sector, although unlikely to disappear, is unstable, with successive themes coming and going (e.g. development, food security, gender) - and, with them, jobs appearing and disappearing. The elite seems aware of the way that their public statements on culture, on women's rights and on AIDS have pragmatic purposes in positioning them for new employment should their current jobs end. In other words, by maintaining a narrative of the blame for AIDS that focuses on harmful cultural practices the elite can ensure the stability of the policy and programmes directed to reduce transmission and their jobs remain intact. 


\section{The Context}

The main period of fieldwork for this study coincided with an exceptional moment in the Government of Malawi's response to AIDS. In 2006, the Law Commission received two submissions from the National AIDS Commission (NAC) and the Department of Nutrition, HIV/AIDS, requesting the development of legislative framework governing issues related to HIV/AIDS. A Special Law Commission was established in 2007, representing public and private sectors and people living with AIDS. A reform process started in 2007, when a decision was made to create new legislation rather than incorporate HIV/AIDS into existing pieces of legislation (P18).

Objectives of the legislation were to strengthen institutional structures dealing with HIV/AIDS; entrench human rights protection with respect to HIV/AIDS for those affected and infected; introduce criminal sanctions related to HIV infection or conduct and actions that promote infection; and consider entrenching the public health concerns relating to HIV/AIDS as a disease (Malawi Law Commission 2008). Broad areas covered by the legislation include the institutional framework; gender and HIV/AIDS; human rights and HIV/AIDS; education and HIV/ AIDS; information and HIV/AIDS; public health and HIV/AIDS; employment and HIV/AIDS; and criminal law and HIV/AIDS (Malawi Law Commission 2008).

According to the Law Commission, 'the vulnerability of women and girls to HIV/AIDS is aggravated by certain cultural and religious practices' $(2009$, p. 33$)$. The legislation intended to prohibit or regulate harmful practices that pose a risk of infection with HIV and other Sexually Transmitted Infections (STIs). It also addressed the issue of subjecting others to harmful practices. The Law Commission identified eighteen cultural practices. These include Chibaro (marrying the wife of a deceased brother); Chimwanamaye (exchanging of husbands or wives); kulowa kufa (cleansing after death). In my interviews, respondents featured fisi, which means 'hyena' in English, has two meanings. First, a man (who is referred to as fisi) is chosen by the village leader to have sex with young girls at initiation ceremonies. Second, a fisi can also be a man hired by a family to have sex with a married woman who cannot conceive, and therefore a secret arrangement is made with the fisi (see Chapter 4 for more details about the legislation). 
These practices are considered to be contributing factors to the spread of AIDS (Kalipeni and Garrard 2004; College of Medicine 2005; Munthali et al. 2006; Kadzandira and Zisiyana 2006; Chimombo 2006; Conroy et al. 2006). The legislation referring to human rights proposes to prohibit discrimination on the basis of HIV/AIDS-whether perceived or actual - and to provide for rights of persons infected with HIV or suffering from AIDS. Finally, the criminal law legislation aims to create offences on deliberate transmission and to create differentiated categories from deliberate to negligent and reckless acts or omissions (Malawi Law Commission 2008).

Policies regarding sexual cultural practices became projects. Policies and projects are constructed by donors and by the Government of Malawi to eradicate or modify practices. They have vested interests and pursue their own agendas. Donors globally are pursuing the human rights agenda, promoting gender equality and the rights of women and girls, as set out by international frameworks such as the UN's Convention on the Elimination of all Forms of Discrimination Against Women. Donors think they are pursuing these policies in order to reduce AIDS in Malawi and thereby improving the health and well-being of the population: in particular that of girls and women subjected to these practices. The Government and NGOs' agenda is to maintain funding from donors so that the Malawian elites can hold on to their positions and the associated lifestyle.

\section{Methodological Approach}

The main aim of my research was to examine how policies on HIV prevention and harmful cultural practices have come to be linked. I identified five objectives to meet this aim. First, I assessed the extent to which the epistemic community in Malawi reframed the AIDS epidemic to further their goals and self-interests. Second, I investigated whether the debates within the epistemic community are facilitated or constrained by international donors (bi- and multilateral agencies). Third, I explored whether or not AIDS is being represented as an exceptional circumstance, justifying policies that would not normally be applied to other public health crises, for example, STIs such as gonorrhoea or syphilis. Fourth, I examined the extent to which international frameworks, agendas and paradigms are influencing and impacting on traditional cultural 
practices and women's rights, resulting in changes to legislation to ban such practices. And finally, I assessed the implications of the findings for the conceptualisation and provision of future and current AIDS policies and programmes in Malawi. The overall rationale for these research questions is that future HIV prevention programmes will be more effective and based on rigorous scientific evidence.

I identified five research questions to complete this study: (i) how are epistemic communities framing and/or reframing the AIDS epidemic to further their goals and self-interests (such as keeping themselves in jobs)?; (ii) how are the debates within the epistemic community facilitated or constrained by international donors (bi- and multilateral agencies)?; (iii) to what extent are HIV/AIDS being represented as exceptional circumstances, justifying policies that would not normally be applied to different public health crises?; (iv) how are international frameworks, agendas and paradigms influencing and impacting on traditional cultural practices and women's rights, resulting in changes to legislation to ban such practices?; and (v) what are the implications for AIDS policies and programmes in Malawi?

The data emerges from research in Malawi from 2008-2009. In order to understand how constructions of narratives linking AIDS and sexual cultural practices came about, I conducted 60 in-depth interviews in four districts: Balaka $(n=15)$, Blantyre $(n=7)$, Lilongwe $(n=34)$, and Zomba $(n=4)$-with expatriates and Malawians working on HIV prevention including lawyers, researchers, policymakers, government ministers, NGO staff, national and district officials and health workers. I interviewed 39 men and 21 women. All respondents were Chewa.

I asked questions relating to themselves, their profession and what they liked and disliked about it, to find out about their lives as development professionals. Questions then focused on the themes of cultural practices, gender and AIDS to find out to what extent they thought cultural practices contributed to the spread of AIDS. I used snowball sampling to identify respondents which enabled them to be easily identifiable, willing to be interviewed and generous with suggestions of others to interview. Having positioned myself in one of the biggest AIDS NGOs in Malawi for several months, it was relatively straightforward to identify respondents at an early stage.

Interviews were either recorded or I made notes and transcribed. Analysis of interview transcripts and field notes took an inductive 
approach and data were analysed adopting elements from grounded theory. These 60 in-depth interviews were the main data source used in this book and these data were coded; patterns in the data identified by means of thematic codes and each code compared to other codes to identify similarities and differences. I coded for key issues (fisi, what respondent say are bad about cultural practices, what they say in a general way about harmful cultural practices, their religion and ethnicity). Key issues emerged as a result of reading the interview transcripts many times and these issues became the major findings of the wider study.

These data were one component of a wider ethnography. I lived with Malawian development professionals, kept journal notes, visited two main newspaper headquarters and photocopied newspaper articles spanning 10 years covering stories on AIDS. Further I collected policy documents (which were often difficult to get hold of), attended meetings and conferences in Malawi and talked to many people. I worked as a consultant for UNAIDS to see how organisations' AIDS policies were 'harmonised and aligned' with Malawi's HIV prevention strategy, for which I conducted 28 semi-structured interviews with people working on HIV prevention. These data fed into my overall findings. The argument I present in this book is evidenced by my critical analysis of interviews, newspaper articles, policy documents as well as secondary academic sources.

I aligned my research with the interpretivist paradigm to include ontological, epistemological and methodological assumptions as acknowledged by Guba and Lincoln (1994, pp. 107-108). According to Mertens, 'a researcher's theoretical orientation has implications for every decision made in the research process, including the choice of method' (2005, pp. 3-4). Methods traditionally associated with the interpretivist approach are mainly qualitative and can include participant observation, focus group discussions, action research, ethnography, phenomenology and discourse analysis. A qualitative rather than a quantitative approach was therefore undertaken for this research as I investigate the opinions, interpretations, beliefs, values and attitudes of agencies rather than the collection of statistical data. This approach also enabled the collection of rich data to critique the response to HIV prevention in Malawi at the time the fieldwork took place.

Qualitative research methods were the main methods used in this study. I decided to use qualitative methods because I conducted 
research on people's views on AIDS and sexual cultural practices, therefore it was necessary to look at the social, political and cultural factors which may influence a person's view. The best way to obtain data to analyse the impact of such factors is the use of methods such as participant observation or ethnographic research. This approach allows the researcher to get inside the skin of his or her research subjects. The researcher is then taking on more of a learning role as opposed to a scientific testing role (Silverman 1993) as s/he is observing the situation in context. This approach also allowed me to obtain data that cannot be retrieved by using methods typically associated with positivism (e.g. statistical modelling or fixed choice questions to random samples).

\section{STRUCTURE OF THE BoOK}

I start with a review of how others have thought and written about elites and policymaking. Those readers interested only in the findings of the study on which this book is based could skip straight to Chapter 3 (though they would miss out on some theoretical insights which help to make meaning of the results which follow).

In Chapter 2 I present theoretical perspectives that have informed the study. Due to the interdisciplinary nature of this research, I show how a number of theories influenced by argument. First, using the approaches used within the anthropology of development I provide a critique of HIV policymaking. Second, and in order to understand how policy was constructed based on misconceptions, I draw on elite and policymaking theories to demonstrate how the policy process is being mediated by the agendas of elites as opposed to bio-medical facts. Third, I use postcolonial theory to highlight how the elites are interpreting for themselves the colonial narrative that is founded on a binary opposition; civilised (the elites) and the uncivilised (the rural uneducated population). This then enables the elites to distance themselves from those living in rural areas, allowing them to maintain a position of power and access to the resources flowing in from the aid community.

In Chapter 3 The Development Aid Situation in Malawi, I provide a brief history of the development aid situation, which is given to highlight the reliance of the National Government on external aid to address high prevalence rates. I then demonstrate how the HIV pandemic is widely considered an emergency and I highlight how AIDS has been 
represented as an exceptional circumstance, justifying policies that are unique to this country's context. I analyse HIV and harmful cultural practices in Malawi and explain how, given the epidemiology of HIV, the fisi practice cannot account for the spread of the epidemic.

In Chapter 4 Harmful Cultural Practices' and AIDS, I show how what are called 'harmful cultural practices' have emerged as a development issue in global conventions and policies over the past ten years. I then analyse the shift from the global to the national level and demonstrate how international policy has influenced national policy on harmful cultural practices and AIDS in Malawi. I use data to show how the Malawian elite have constructed narratives of blame concerning AIDS and cultural practices which reflect their view that the backwardness of village people is to blame for high HIV prevalence rates.

In Chapter 5 How the Church Frames AIDS, I explore the link between religion and AIDS and analyse the influence of the church in shaping the views of the Malawian elite. I demonstrate through my interviews how the attendance of Malawian elites at church has influenced the way they think about AIDS, cultural practices and rural people. First, I provide the religious context in Malawi. I explore how religious elites perceive cultural practices as negative and backward, positioned against their Christian beliefs they perceive as enlightened.

In Chapter 6 The Construction of Policy: Donors, AIDS and Sexual Cultural Practices, I analyse the policy construction process and review literature on policymaking processes, concluding that the policymaking process is messy and complex. I argue that stakeholders try to influence HIV policy by using narratives and discourses to pursue their own vested interests, which are presented as knowledge. Additionally, I look at the aid game in Malawi. I then consider how these narratives have been passed on through education. I review donors' perceptions of harmful cultural practices and argue that donors have absorbed narratives of blame linking harmful cultural practices and AIDS because it feeds into and supports the dominant neocolonialist view of the African other as primitive and backward.

In Chapter 7 Conclusion and Recommendations, I argue that my ethnographic approach has enabled me to highlight how 'narratives of blame' are used as a smokescreen to pursue government and donors' interests. I also present policy recommendations and suggestions for future research. 


\section{Notes}

1. For example researchers at MLSFH presented the NAC with their findings on AIDS. They probably never read them as they have to follow donors, not researchers.

2. For example, Ghana; Amoakohene (2004). Kenya; Oluga et al. (2010) and Ayikukwei et al. (2008). Mali; Mackie and LeJeune (2009). Mozambique; Kotanyi and Krings-Ney (2009). Nigeria; Adesina (2015). Sierra Leone; M'jamtu-Sie (2007). South Africa; Oluga et al. (2010). South Africa, Lesotho, and Swaziland; (UNICEF 2003). Tanzania; Wadesango et al. (2011) and Oluga et al. (2010). Uganda; Asiimwe et al. (2003). Zambia; Moyo and Müller (2011).

3. Early in the epidemic Gray et al. (2001) estimated probability of infection at 0.001 . Thus, out of a 1000 people who are not infected with HIV, for every act of unprotected intercourse with a person one is HIV positive.

4. See Norma Anderson (2017) who argues that when development trends and issues in Malawi change, at donors' wishes, organisations proactively strategize to vie for donors. Her data show that between 2008 and 2010 there was a widespread belief among civil society in Malawi that climate change was becoming the 'it' issue, surpassing HIV/AIDS in predominance.

\section{REFERENCES}

Adesina, M. O. (2015). Trado-cultural practices, situation, analysis and epidemiological factors in the spread of HIV/AIDS in Nigeria. Journal of Education and Practice, 6(21), 65-70.

Amoakohene, M. I. (2004). Violence against women in Ghana: A look at women's perceptions and review of policy and social responses. Social Science and Medicine, 59(11), 2373-2385.

Anderson, N. J. (2017). Ephemeral development agendas and the process of priority shifts in Malawi. Journal of Asian and African Studies, 52(7), 915-931.

Asiimwe, D., Kibombo, R., \& Neema, S. (2003). Focus group discussions on social cultural factors impacting on HIV/AIDS in Uganda. Kampala: Makerere Institute of Social Research.

Ayikukwei, R., Ngare, D., Sidle, J., Ayuku, D., Baliddawa, J., \& Greene, J. (2008). HIV/AIDS and cultural practices in western Kenya: The impact of sexual cleansing rituals on sexual behaviours. Culture, Health \& Sexuality, $10(6), 587-599$.

Banda, F., \& Kunkeyani, T. E. (2015). Renegotiating cultural practices as a result of HIV in the eastern region of Malawi. Culture, Health \& Sexuality, 17(1), $34-47$. 
Bassey, M. O. (1999). Western education and political domination in Africa: A study in critical and dialogical pedagogy. Westport, CT: Bergin and Garvey.

Boily, M.-C., Baggaley, R. F., Wang, L., Masse, B., White, R. G., Hayes, R. J., et al. (2009). Heterosexual risk of HIV-1 infection per sexual act: Systematic review and meta-analysis of observational studies. The Lancet Infectious Diseases, 9(2), 118-129.

Chimbiri, A. (2007). The condom is an 'intruder' in marriage: Evidence from rural Malawi. Social Science of Medicine, 64(5), 1102-1115.

Chimombo, S. (2006). The hyena wears darkness. Zomba: WASI Publications.

Chizimba, R., et al. (2004). The development and implementation of the national behaviour change interventions strategy for HIV/AIDS/SRH in Malawi: An evidence-based approach to planning strategic behaviour change interventions. National AIDS Commission, Malawi.

College of Medicine. (2005). Cultural practices related to sexual and reproductive bealth outcomes and HIV transmission. Blantyre: College of Medicine.

Conroy, A., Blackie, M., Whiteside, A., Malewezi, J., \& Sachs, J. (2006). Poverty, AIDS and hunger: Breaking the poverty trap in Malawi. Hampshire: Palgrave Macmillan.

Coombes, Y. (2001). A literature review to support the situational analysis for the national behaviour change interventions strategy on HIV/AIDS and sexual and reproductive health. London: DFID.

Crewe, E., \& Harrison, E. (1998). Whose development? An ethnography of aid. London: Zed.

Dimbuene, Z. T., Emina, J. B., \& Sankoh, O. (2014). UNAIDS 'multiple sexual partners' core indicator: Promoting sexual networks to reduce potential biases. Global Health Action, 7(1), 23103.

Escobar, A. (1988). Power and visibility: Development and the intervention and management of the third world. Cultural Anthropology, 3(4), 428-443.

Escobar, A. (1995). Encountering development: The making and unmaking of the third world. Princeton, NJ: Princeton University Press.

Gibson, C. C., Andersson, K., Ostrom, E., \& Shivakumar, S. (2005). The Samaritan's dilemma: The political economy of development aid. Oxford: Oxford University Press on Demand.

Gramsci, A., \& Hoare, Q. (1971). Selections from the prison notebooks (Vol. 294). London: Lawrence and Wishart.

Gray, R. H., Wawer, M. J., Brookmeyer, R., Sewankambo, N. K., Serwadda, D., Wabwire-Mangen, F., ... \& Quinn, T. C. (2001). Probability of HIV-1 transmission per coital act in monogamous, heterosexual, HIV-1-discordant couples in Rakai, Uganda. The Lancet, 357(9263), 1149-1153.

Guba, E. G., \& Lincoln, Y. S. (1994). Competing paradigms in qualitative research. Handbook of Qualitative Research, 2(163-194), 105.

Haas, P. M. (1992). Epistemic communities and international policy coordination: Introduction. International Organisation, 46(1), 1-35. 
Harper, R. H. (1998). Inside the IMF: An ethnography of documents, technology and organisational action. London and New York: Routledge.

Hobart, M. (1993). An anthropological critique of development: The growth of ignorance. London: Routledge.

Joint United Nations Programme on HIV/AIDS (UNAIDS). (2013). Progress report on the global plan towards the elimination of new HIV infections among children by 2015 and keeping their mothers alive. Geneva: UNAIDS.

Kadzandira, J. M., \& Zisiyana, C. (2006). Assessment of risk practices and sites where such practices take place in the urban areas of Lilongwe and Blantyre districts. Zomba: Centre for Social Research.

Kalipeni, E., \& Garrard, C. (Eds.). (2004). HIV/AIDS in Africa: Beyond epidemiology. Oxford and Cambridge: Blackwell.

Kamlongera, A. (2007). What becomes of 'her'? A look at the Malawian fisi culture and its effects on young girls. Agenda, 21(74), 81-87.

Kitching, G. (1982). Development and underdevelopment in historical perspective. New York: Methuen.

Koch, D. J. (2007). Uncharted territories: The geographical choices of aid agencies. The Broker, 1(3), 9-12.

Kornfield, R. \& Namate, D. (1997). Cultural practices related to HIV/AIDS risk behaviour: Community survey in Phalombe, Malawi (No. 10). Support to AIDS and Family Health (STAFH) Project 612-238.

Kotanyi, S., \& Krings-Ney, B. (2009). Introduction of culturally sensitive HIV prevention in the context of female initiation rites: An applied anthropological approach in Mozambique. African Journal of AIDS Research, 8(4), 491-502.

Lloyd, P. C. (1967). Africa in social change: Changing traditional societies in the modern world. Baltimore: Penguin Books.

Mackie, G., \& LeJeune, J. (2009). Social dynamics of abandonment of harmful practices: $A$ new look at the theory (Innocenti Working Paper No. XXX). Florence: UNICEF Innocenti Research Centre.

Malawi Demographic and Health Survey. (2004). Maryland: NSO and ORC Macro.

Malawi Human Rights Commission. (2006). Cultural practices and their impact on the enjoyment of human rights, particularly the rights of women and children in Malawi. MHRC: Malawi.

Malawi Law Commission. (2008). Report of the Law Commission on the development of HIV and AID legislation. Lilongwe: Malawi.

Matinga, P., \& McConville, F. (2003). A review of cultural beliefs and practices influencing sexual and reproductive bealth and bealth-seeking behaviour, in Malawi. Malawi: Department for International Development (DFID).

Mertens, D. M. (2005). Research methods in education and psychology: Integrating diversity with quantitative and qualitative approaches ( $2 \mathrm{nd} \mathrm{ed}$.$) .$ Thousand Oaks: Sage. 
Mishra, V., Bignami-Van Assche, S., Greener, R., Vaessen, M., Hong, R., Ghys, P. D., et al. (2007). HIV infection does not disproportionately affect the poorer in sub-Saharan Africa. AIDS, 21(Supp.7), S17-S28.

M'jamtu-Sie, N. (2007). The impact of culture and tradition on attitudes to health in Sierra Leone. Journal of Hospital Librarianship, 6(4), 93-107.

Morfit, S. (2008). Dangerous development: The global response to AIDS in Africa. Unpublished Master's Paper, Department of Sociology, University of California, Berkeley.

Morfit, N. S. (2011). "AIDS is money": How donor preferences reconfigure local realities. World Development, 39(1), 64-76.

Mosse, D. (2004). Is good policy unimplementable? Reflections on the ethnography of aid policy and practice. Development and Change, 35(4), 639-671.

Mosse, D. (2005). Cultivating development: An ethnography of aid policy and practice. London \& Ann Arbor, MI: Pluto Press.

Mosse, D. (2011). Introduction: The anthropology of expertise and professionals in international development. In D. Mosse (Ed.), Adventures in Aidland. Oxford: Berghahn Books.

Moyo, N., \& Müller, J. C. (2011). The influence of cultural practices on the HIV and AIDS pandemic in Zambia. HTS Theological Studies, 67(3), 412-417.

Munthali, A. C., \& Zulu, E. M. (2007). The timing and role of initiation rites in preparing young people for adolescence and responsible sexual and reproductive behaviour in Malawi. African Journal of Reproductive Health, 11(3), 150.

Munthali A. C., Moore, A., Konyani, S., \& Zakeyo, B. (2006). Qualitative evidence of adolescents' sexual and reproductive health experiences in selected districts of Malawi. New York: The Alan Guttmacher Guttmacher Institute.

Myroniuk, T. W. (2011). Global discourses and experiential speculation: Secondary and tertiary graduate Malawians dissect the HIV/AIDS epidemic. Journal of the International AIDS Society, 14(1), 47.

NSO, M., \& Macro, I. C. F. (2011). Malawi demographic and health survey 2010. Zomba, Malawi and Calverton, MD: NSO and ORC Macro.

OECD-DAC, D. A. C. (2007). Action-Oriented Policy Paper on Human Rights and Development.

Oluga, M., Kiragu, S., Mohamed, M. K., \& Walli, S. (2010). 'Deceptive' cultural practices that sabotage HIV/AIDS education in Tanzania and Kenya. Journal of Moral Education, 39(3), 365-380.

Quarles van Ufford, P., \& Saleminck, O. (2006). After the fall: Cosmopolitanism and the paradoxical politics of global inclusion and authenticity. Paper prepared for the panel on cosmopolitanism and development. Association of Social Anthropologists Diamond Jubilee Conference, Keele, UK.

Silverman, D. (1993). Interpreting qualitative data. London: Sage. 
Skinner, J., Underwood, C., Schwandt, H., \& Magombo, A. (2013). Transitions to adulthood: Examining the influence of initiation rites on the HIV risk of adolescent girls in Mangochi and Thyolo districts of Malawi. AIDS Care, 25(3), 296-301.

Smith, K. P., \& Watkins, S. C. (2005). Perceptions of risk and strategies for prevention: Responses to HIV/AIDS in rural Malawi. Social Science and Medicine, 60(3), 649-660.

UN. (2006). Human Development Report. New York: UN.

UN. (2010). Human Development Report. New York: UN.

UNAIDS. (2004). Women and HIV/AIDS: Confronting the crisis. Geneva: UNAIDS.

UNICEF. (2003). Child protection: An analysis and achievements in 2003. New York: UNICEF.

Wa Thiong'o, N. (1986). Decolonizing the mind: The politics of language in African literature. London: Heinemann Educational Books.

Wadesango, N., Rembe, S., \& Chabaya, O. (2011). Violation of women's rights by harmful traditional practices. The Anthropologist, 13(2), 121-129.

Watkins, S. C., \& Swidler, A. (2009). Hearsay ethnography: Conversational journals as a method for studying culture in action. Poetics, 37(2), 162-184.

Watkins, S. C., \& Swidler, A. (2013). Working misunderstandings: Donors, brokers, and villagers in Africa's AIDS industry. Population and Development Review, 38, 197-218.

Wood, P. (1998). The rise of consultancy and the prospect for regions. Paper presented at the 38th congress of the European Regional Science Association, Vienna, 28-31. 
Open Access This chapter is licensed under the terms of the Creative Commons Attribution 4.0 International License (http://creativecommons.org/licenses/ by $/ 4.0 /$ ), which permits use, sharing, adaptation, distribution and reproduction in any medium or format, as long as you give appropriate credit to the original author(s) and the source, provide a link to the Creative Commons licence and indicate if changes were made.

The images or other third party material in this chapter are included in the chapter's Creative Commons licence, unless indicated otherwise in a credit line to the material. If material is not included in the chapter's Creative Commons licence and your intended use is not permitted by statutory regulation or exceeds the permitted use, you will need to obtain permission directly from the copyright holder.

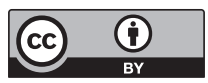

